\title{
A framework for the design of reacting systems with phase transfer catalysis
}

\author{
Piccolo, Chiara; Shaw, Andrew; Hodges, George; Piccione, Patrick M.; O'Connell, John P.; Gani, Rafiqul
}

Published in:

Proceedings of the 22nd European Symposium on Computer Aided Process Engineering

Publication date:

2012

Link back to DTU Orbit

Citation (APA):

Piccolo, C., Shaw, A., Hodges, G., Piccione, P. M., O'Connell, J. P., \& Gani, R. (2012). A framework for the design of reacting systems with phase transfer catalysis. In I. D. L. Bogle, \& M. Fairweather (Eds.), Proceedings of the 22nd European Symposium on Computer Aided Process Engineering (pp. 757-761). Elsevier. Computer Aided Chemical Engineering Vol. 30

\section{General rights}

Copyright and moral rights for the publications made accessible in the public portal are retained by the authors and/or other copyright owners and it is a condition of accessing publications that users recognise and abide by the legal requirements associated with these rights.

- Users may download and print one copy of any publication from the public portal for the purpose of private study or research.

- You may not further distribute the material or use it for any profit-making activity or commercial gain

- You may freely distribute the URL identifying the publication in the public portal 
Ian David Lockhart Bogle and Michael Fairweather (Editors), Proceedings of the 22nd European Symposium on Computer Aided Process Engineering, 17 - 20 June 2012, London.

(C) 2012 Elsevier B.V. All rights reserved

\title{
A framework for the design of reacting systems with phase transfer catalysis
}

\author{
Chiara Piccolo ${ }^{\mathrm{a}}$, Andrew Shaw ${ }^{\mathrm{b}}$, George Hodges ${ }^{\mathrm{b}}$, Patrick M. Piccione ${ }^{\mathrm{b}}$, John P. \\ $\mathrm{O}^{\prime}$ Connell ${ }^{\mathrm{c}}$, Rafiqul Gani ${ }^{\mathrm{a}}$ \\ ${ }^{a}$ CAPEC, Department of Chemical \& Biochemical Engineering, Technical University of \\ Denmark, 2800 Kgs. Lyngby, Denmark (rag@kt.dtu.dk) \\ ${ }^{b}$ Process Studies Group, Syngenta, Jealott's Hill International Research Center, Bracknell, \\ Berkshire RG42 6EY, United Kingdom \\ ${ }^{c}$ Department of Chemical Engineering, University of Virginia, Charlottesville, Virginia, USA
}

\begin{abstract}
A generic modelling framework for phase transition catalyst based reacting systems has been developed and converted into a software tool. The modelling framework accommodates models of different types representing different sub-systems of the PTCbased reactive system; databases of model parameters and carefully collected and checked (for thermodynamic consistency) experimentally measured data. The models, data and software have been tested on various PTC-based reactive systems. Illustrative examples are provided.
\end{abstract}

Keywords: Phase transfer catalysis, modelling, partition coefficient, solubility, design/analysis

\section{Introduction}

The objective of this paper is to present a methodology for the design, selection and evaluation of phase transfer catalyst (PTC) based processes and a software tool, called PTC-Virtual Lab (PTC-VLab), which follows this methodology. Although, the PTCbased processes are now a mature technology for synthesis of organic chemicals from two reactants located in immiscible phases, nevertheless, they are sufficiently complex involving a number of modelling and design challenges. For example, they involve several interacting phenomena, such as, reactions taking place in a solvent phase as well as an aqueous phase; the catalyst having an active-form and a spent-form; and the solubilities of the active- and spent-forms of the PTC in the solvent and water (in the presence of inorganic salts). To design and analyze the operations of a PTC-based reaction process, it is necessary to understand the partition coefficients of the PTC in the different phases and how these would influence the reaction. Also, the choice of the solvent is important. In the absence of reliable model-based techniques, these processes have been mainly studied (and designed) based on experiments. This explains why there are no simple guidelines for the design, evaluation and optimization of PTC based operations. At the same time, the higher number of degrees of freedom for fine tuning reaction conditions suggests that systematic model-based methodologies should be developed to enable a systematic optimization of PTC processes.

The first step in developing any model-based design methodology is to analyze and understand the process and based on it, develop a reliable model. Then a work-flow and data-flow related to the main steps of the design methodology needs to be established and tested with application examples. Then the established work-flow and data-flow are converted into a model-based software tool. The objective of the PTC-Virtual Lab is to 
allow the user to generate, screen and evaluate process alternatives, based on the selection of different catalysts, organic solvents and operational conditions. It should be able to predict the concentrations of reactants and products in the two co-existing phases, as well as provide the estimation of physical parameters of the PTC parameters, such as, partition coefficients and catalyst and solvent mutual solubilities. The software should allow the user to study/analyze fundamental physical property data of the catalyst and the involved chemicals; design, analyze and evaluate alternative operating conditions; select, analyze and evaluate solvents, PTC for a specified reaction.

In an earlier work [1], the authors proposed an efficient and consistent thermodynamic framework that enabled the estimation of the partition coefficients by decomposing the complex chemical system into four different binary sub-systems: In this work, this model has been further extended in terms of application range, checked for thermodynamic consistency, and, based on these, the PTC-Virtual lab has been developed.

\section{Model-based Methodology}

\subsection{Fundamentals}

Figure 1 illustrates a typical biphasic PTC system. RX is the substrate. Q+Y- is the active form of the $\mathrm{Q}+\mathrm{X}$ - is the spent form of the PTC and the RY is the desired product. The spent form of the PTC is soluble in an aqueous electrolyte solution where the active form the PTC is generated. $\mathrm{M}+\mathrm{X}-$ and $\mathrm{M}+\mathrm{Y}-$ are inorganic salts that dissociate in water. The reaction takes place in the solvent phase while the generation of the active form of the PTC takes place in the aqueous phase.

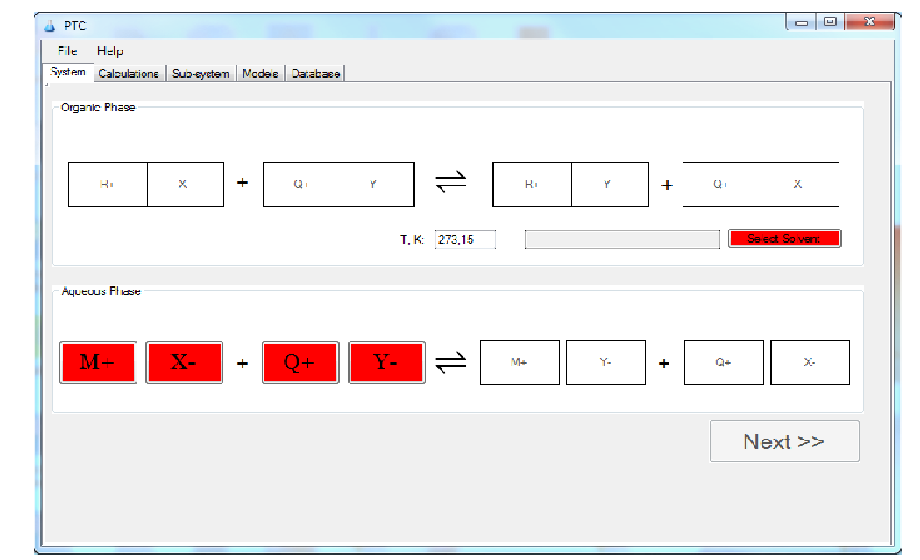

Figure 1 Mechanism for a typical Nucleophilic substitution reaction

Typically, as pointed out by Piccolo et al [1], this biphasic system can be decomposed into four sub-systems: a) water-organic solvent equilibrium, b) inorganic salt (source of reactive anion)-water, c) phase transfer catalyst-organic solvent, d) phase transfer catalyst-water. For each sub-system, data have been collected and representative models to calculate the liquid phase activity coefficients and from it, the solubilities and phase equilibrium, have been developed and tested for the systems of interest.

\subsection{Model development and verification}

An overview of the models and data are given through Table 1. Details of the phase equilibrium models for each phase and the combined system can be found in Piccolo et 
al. [1] and therefore not given here. Instead, the consistency of the collected data and the modelling assumptions has been verified.

Table 1: Overview of the systems studied

\begin{tabular}{|l|l|l|l|l|}
\hline & Sub-system A & Sub-system B & Sub-system C & Sub-system D \\
\hline $\begin{array}{l}\text { Data of binary } \\
\text { systems }\end{array}$ & 9 & 10 & 63 & 42 \\
\hline Data-points & 494 & 271 & 65 & 89 \\
\hline Model for $\chi$ & $\begin{array}{l}\text { UNIFAC; NRTL; } \\
\text { UNIQUAC }\end{array}$ & $\begin{array}{l}\text { e-NRTL; } \\
\text { e-UNIQUAC }\end{array}$ & UNIFAC-IL* & e-NRTL** \\
\hline Model type & Predictive & Correlative & Predictive & Correlative \\
\hline
\end{tabular}

* Model developed for this work; ** Model parameters estimated for this work

For systems A and B, the 9 and 10 systems, respectively, of interest to Syngenta have been tested and the models have been found to give acceptable values. A more detailed analysis of systems $\mathrm{C}$ and $\mathrm{D}$ are given below.

System C: The database of infinite dilution coefficient has been expanded using a procedure suggested by a series of paper by Abraham and coworkers [2, 3, 4] based on free energy of transfer values. These values provide a direct measure of the partition of the compounds of interest between two different phases and can be used to define a procedure to estimate the solubility of the PTCs if not experimentally available. Moreover the procedure allows to calculate the values of $\gamma_{i}^{\infty}$ (i=PTC) in the organic phase which can be compared to those derived through Eq. 1.

$$
x_{i} \gamma_{i}=\exp \left(\frac{\Delta H_{f}}{R T_{m}}\left(1-\frac{T_{m}}{T}\right)+\frac{\Delta H_{t r I}}{R T_{t r I}}\left(1-\frac{T_{t r I}}{T}\right)+\frac{\Delta H_{t r I I}}{R T_{t r I I}}\left(1-\frac{T_{t r I I}}{T}\right)\right)
$$

Using the generated infinite dilution activity coefficient values for different PTCs in different solvents, a new version of UNIFAC-IL has been developed. Using the knowledge of equilibrium condition of a solute partitioning between an organic and an aqueous phases and applying the Raoult's law in the standard state, it can be shown that if the organic phase is sufficiently dilute, it is possible to calculate out the infinite dilution activity coefficient of $I$ in the organic phase through Eq. 2 (where $\Delta G_{t}$ is the free Gibbs energy of transfer from water to the organic solvent).

$\gamma_{i, s}^{\infty}=\frac{x_{i, w} \gamma_{i, w}^{*}}{x_{i, s}}=\exp \left[-\frac{\Delta G_{t}}{R T}\right]$

System D: This work has been divided into two sections - a section involving PTC (with counter ions $\mathrm{Br}^{-}, \mathrm{Cl}^{-}, \mathrm{I}^{-}$) and water; and PTC (other counterions such as $\mathrm{OH}^{-}$) and water. For the first section, the e-NRTL parameters have been found to be quite satisfactory. For the second section, a more detailed analysis was necessary. The procedure for the estimation of parameters for these PTC-water systems has been checked in terms of the following:

a. The salt concentrations in water - since it is not high enough, a simple extended Debye-Huckel model should be able to provide a sufficiently accurate estimate of the dependence of the mean activity coefficient of the PTC in water on the concentration. 
b. Also, in case of the need for extra data, the Guggheneim parameters [5] could be used to generate pseudo-experimental data. Additvity of ions to estimate parameters for missing salts is valid under these conditions.

The sub-systems models are integrated in a continuous reactor model so that a quick evaluation of the process behaviour at different operational conditions is possible. For design/analysis of a PTC process, the system of interest needs to be defined (catalyst/organic solvent/inorganic salt). The framework checks for data, model and parameters to prepare a consistent model, and then guides the user through the design/analysis steps of the algorithm. Calculated values of solubilities, partition coefficients, and the distribution of the PTC, solvents, reactants and products in the different phases are returned. In this way, effects of the operational variables on these calculated variables can be investigated.

\subsection{Partition Coefficient}

The partition coefficients, defined as the ratio of the concentrations of a compound in the two phases at equilibrium, needed for the PTC-based process are the following: $\mathrm{K}_{\mathrm{W}}$ (water), $\mathrm{K}_{\mathrm{S}}$ (solvent), $\mathrm{K}_{\mathrm{Q}+\mathrm{Y}-}$ (active PTC) and $\mathrm{K}_{\mathrm{Q}+\mathrm{X}-}$ (spent-PTC). They are calculated through Eqs. 3-6.

$K_{s}=\frac{x_{s}^{o r g}}{x_{s}^{a q}}=\frac{\gamma_{s}^{a q}}{\gamma_{s}^{\text {org }}}$

$K_{Q+Y-}=\frac{x_{Q+Y-}^{o r g}}{x_{Q+Y-}^{a q}}=\frac{\gamma_{Q+Y-}^{a q}}{\gamma_{Q+Y-}^{\text {org }}}$

$$
\begin{aligned}
& K_{w}=\frac{x_{w}^{o r g}}{x_{w}^{a q}}=\frac{\gamma_{w}^{a q}}{\gamma_{w}^{o r g}} \\
& K_{Q+X-}=\frac{x_{Q+X-}^{o r g}}{x_{Q+X-}^{a q}}=\frac{\gamma_{Q+X-}^{a q}}{\gamma_{Q+X-}^{o r g}}
\end{aligned}
$$

\section{PTC-Virtual Lab \& Application}

The software contains a suite of databases with solubility data of the different binary sub-systems, representing the total system. Models are selected from a library of available and validated models for performing solubility equilibrium calculations for each of the identified sub-systems, based on the intrinsic system features (dissociating or not dissociating system). The appropriate design algorithm is used after the needed interaction parameters are retrieved from the databases, or estimated, if not available, without requiring additional experimental data. That is, for a selected model and subsystem, the necessary model parameters are retrieved and/or estimated using a thermodynamically consistent parameter estimation procedure that allows the use of data for other systems (if the system specific data are not available) having the same characteristic ions as the system under investigation. All the data and models listed in Table 1 are available in PTC-Vlab. Figure 1 also shows a screen shot of PTC-Vlab highlighting the different phases and the visual input of data by the user. In Fig. 1, the red-boxes indicate the data that needs to be given by the user and the white boxes are calculated. The option "calculations" performs calculations of phase equilibria for different sub-systems, partition coefficients, etc.; option "database" allows search for solvents, PTCs, sus-system data, etc.; and, option "models" allows the user to analyze the model and/or to fine-tune the model parameters.

\subsection{Application examples}

Results from the applications of the PTC-Vlab to three problems are presented below. These examples highlight the predictive nature of the models and the implemented tools in the sense that the conditions and PTC can be changed for the same reaction without requiring the model parameters to be regressed from experimentally measured data. Table 3 gives the details for the systems involved in each problem. The organic phase 
reaction is the same, i.e. the conversion of benzyl chloride (RX) into benzyl bromide (RY). Table 4 gives the estimated partition coefficients.

Table 3: System description for the PTC-based systems

\begin{tabular}{|l|l|l|l|l|l|l|}
\hline Problem & Solvent & $\begin{array}{l}\text { Inorganic } \\
\text { salts }\end{array}$ & $\begin{array}{l}\text { PTC- } \\
\text { active }\end{array}$ & $\begin{array}{l}\text { PTC- } \\
\text { spent }\end{array}$ & $\begin{array}{l}\text { Temperature } \\
(\mathrm{K})\end{array}$ & $\begin{array}{l}\text { Final } \\
\text { conversion }\end{array}$ \\
\hline 1 & Benzene & $\mathrm{NaBr}, \mathrm{NaCl}$ & TBABr & TBACl & 298 & $28.4 \%$ \\
\hline 2 & Benzene & $\mathrm{NaBr}, \mathrm{NaCl}$ & TBABr & TBACl & 323 & $31.3 \%$ \\
\hline 3 & Benzene & $\mathrm{NaBr}, \mathrm{NaCl}$ & TMABr & TMACl & 298 & $3.7 \%$ \\
\hline
\end{tabular}

For the above systems, in addition to identifying the models and the parameters needed, the following data needs to be given: The aqueous feed (water, salts) and organic feed (solvent plus substrate and PTC). PTC-Vlab then calculates the aqueous phase and organic phase product compositions, and from it, the partition coefficients. Note that a system of 17 non-linear simultaneous algebraic equations (plus constitutive model equations for each sub-system that are calculated as procedures) is generated and solved, giving the compositions of the products in the two co-existing phases. The partition coefficients given in Table 4 have been calculated using the following equations.

Table 4: Calculated partition coefficients for the three problems

\begin{tabular}{|l|l|l|l|l|}
\hline Problem & Kbz & Kw & KTBC,+ Br- & KPTC+,Cl- \\
\hline 1 & 2462.00 & 0.0030 & 0.0104 & 0.0052 \\
\hline 2 & 2095.77 & 0.0066 & 0.0123 & 0.0054 \\
\hline 3 & 2462.00 & 0.0030 & 0.0004 & 0.0012 \\
\hline
\end{tabular}

\section{Conclusions \& Future Work}

Based on the calculated conversions, it is clear that a larger anion for the PTC favours the considered reaction. Also, a higher temperature favours the conversion. Interested readers can obtain the effects of solvents, and PTC-anion chain length on the conversion of the substrate. The models have already been tested. Now the predictive powers of the models are being further extended and the sensitivity of the many model parameters determined together with generating estimates of uncertainty in the predictions and their effect on design of the PTC-based processes.

\section{Acknowledgement}

This project has been funded by Syngenta.

\section{References}

[1] C. Piccolo, G. Hodges, P.M. Piccione, R. Gani, 2011, Computer Aided Chemical Engineering, 29, 266-270.

[2] M.H. Abraham, 1970, Tetrahedron Letters, 60, 5233-5236.

[3] M.H. Abraham, 1971, Journal of the Chemical Society (B) Physical Organic, 299308.

[4] M.H. Abraham, 1972, Journal of the Cemical Society, Perkin Transactions 2, 10, 1343-1357.

[5] J.E. Prue, A.J. Read, G. Romeo, Transactions of the Faraday Society, 1971, 67, $420-427$ 